\title{
Regional specific features of architectural space ecologization for preschool education in the Urals
}

\author{
Natalia Lamekhova* \\ Ural State University of Architecture and Art, Russia
}

\begin{abstract}
The article is concerned with the study of methods on architectural space ecologization for preschool education in Ural region of Russia. The main goal of introducing architectural methods is to educate the child in the correct attitude toward nature, to form a basic reference point in the education of preschool children by architectural means.
\end{abstract}

\section{Introduction}

The lack of communication with nature - a burning issue of today. Children began to spend less time with their families, and more - in front of TV, computer and telephone screen. Any child knows more about their childhood idols from the cartoon series than about nature. At the same time, nature-deficit disorder is the price one pays for detachment. As a result, it manifests itself in deterioration of the senses, attention problems, an increase in physical and mental illnesses, including obesity. Any child needs nature for the development of feelings and creative function.

\section{Materials and Methods}

Landscaping in modern architectural practice is currently suffering major changes and acts as a structural element more than as an element that performs aesthetic functions. This circumstance proves the growing role of landscaping as a structural component in architectural environment formation, exerting a positive effect not only on the psychological state of a person, but also on physical well-being [1 - 5]. Particular attention should be paid to objects for preschool education, demonstrating experience and attitudes toward nature, as a kind of standard of environmental culture for the younger generation. The improvement of ecological component of objects of this kind will be the growth of qualitative characteristics by means of including various methods for architectural space ecologization.

\footnotetext{
*Corresponding author: lamekhova@mail.ru
} 


\subsection{Features of environmental culture formation}

Childhood - one of the most important periods in the life of any person. At this age, a person is most susceptible to the perception of information in life, being an "open" system, absorbing absolutely everything that surrounds him. At the same time, translating the right approach to nature is at odds with upbringing and education. And to a large extent, this circumstance depends on the conditions where preschool children are - in preschool educational institutions. The architectural environment of existing buildings for preschool education is largely outdated, and new approaches require comprehensive study and forward-looking solutions.

The problem of natural deficiency is very acute today, which requires a comprehensive approach and high professionalism from specialists in various fields [6-8]. This fact, increases the speed of decision-making, the development of tools that would help to solve a number of problems at the level of preservation of two components of the architectural space, such as nature conservation and health conservation. In this regard, the architectural environment for preschool education is to be considered as a kind of model, which includes these qualities, and the model, translating a system of environmental values, resulting from interaction of positive-creative, positive-creative principles of detail children, aimed at harmonizing interests and the correct interaction of "man-nature".

The functions of the health -saving space are based on taking into account the development of:

- child's physiological characteristics (these include: age needs and physiological capabilities). For example, the need to learn to walk on a small inclined surface (for children under 2 years) or to roll down an inclined surface (for children under 3-4 years), to master running on an inclined surface (for children from 5-7 years), etc;

- child's psycho-emotional characteristics (need for children in protective function of space - presence of "quiet corners", "quiet zones", the need for social contact - the presence of zones of active games, areas for competitions), etc.;

The process of forming a correct worldview in preschool children, pursuing, spiritual formation of the personality, based on the subjective attitude to nature in preschool children is possible with the inclusion in the educational process of three channels of knowledge of the surrounding world - cognitive (mastering knowledge about the world and man and related activities), perceptive (involvement in the educational process feelings and emotions) and practical (the inclusion of the personality in socially significant, nature-like, creative activities) [9, p. 284].

The functions of an environmentally friendly space are based on taking into account the development of feelings:

- unity with the environment, admiration for it and respect for the processes on which it is built;

- community with other people and living beings;

- responsibility for the made choice;

- developed imagination and creativity;

- continuity between past, present and future;

- ability to find needed information;

- ability to predict and assess [9, p.291].

Features of teaching and educational activities. The task of education, upbringing, and socialization of preschool children is currently one of the highest priorities associated with the modernization of preschool education. This implies the need to improve the architectural environment for preschool education with regard to the environmental approach, within the framework of which children can form the basics of environmental culture - a conscious-right attitude towards phenomena and objects of animate and inanimate nature. 
All of the above arguments prove the importance of essence of the formation of sustainable educational space from perspective of environmentally-oriented methods introduction by incorporating different forms of landscaping.

\subsection{Climatic features of Ural region}

The features of the Ural natural and climatic conditions are due to the meridional direction of the mountain range, which prevents the movement of prevailing westerly air masses, and the large territory length from north to south. Hence the climatic differences between the western and eastern slopes of the Ural Mountains and the Ural plains (climate continentality, sunshine duration, precipitation).

Winter winds are characterized by high stability, their frequency ranges from 40 to $70 \%$. In January, south-western, western and southern winds prevail in the Urals. Protecting facilities from their effects is a serious problem due to the fact that protection from prevailing winds often conflicts with the insolation requirements. Therefore, protection from cold winds can be achieved through the use of natural landscape elements (forest, park, mountains, high river banks, artificially created slopes).

The main goal of space ecologization for preschool education in Ural region is the development of sensitivity to nature, the natural environment and its features in preschool children.

In this regard, preschool institutions with their territory should primarily become zones of ecological safety, which would contribute to the development of successful education in kindergarten, as well as demonstrate a kind of model, which in generalized form reflected the relationship of living and nonliving nature. Thus, the architectural environment of preschool educational institution should be a standard of ecological culture, taking into account the modern requirements of the educational process.

\subsection{Ecologization of architectural space for preschool education}

From perspective of the development and sustainable growth of architectural space that translates the principles of environmentally oriented architectural, environment can be the following:

\subsubsection{Method of territorial defense}

The inclusion of method of territorial protection, which implies, at the level of site formation, the creation of a screen by installing artificial barriers in the form of climbing walls or elements of play and physical education sites. Also, the building volume itself can serve as protective functions (due to plasticity and shape of individual parts).

Territory screening can also be done through the use of natural site forms, the difference in ground level marks, topography and zoning of play activities. The use of natural forms in the site improvement also plays a positive role, because it demonstrates the ability to make do with small and accessible means.

It is also worth mentioning that the monotonous environment affects the person much more, and children need to be protected, so the impact of visual characteristics are in the first place. In nature, there are no right angles, rectangular planes and so on, it is worth striving for smoother forms, rounded corners, demonstrating unity with nature. It is worth trying to recreate them on the site as game elements. The existing imbalance between manmade and natural has a negative impact on the lives of people in general, not to mention children. The development of environmentally oriented architectural environment for 
preschool education should go within the framework of inclusion of site protective functions, the building and the internal component of the architectural space.

Artificially recreated architectural volumes with elements of pitched roofs, slopes can be landscaped, or laid out of different building materials (stone, wood, the combined use of several types of materials), which somehow can be part of landscaping for the purpose of all kinds of outdoor events. Buildings-hills, elevated objects are structures that actively use the site relief. In the process of geoplastics, the site natural reliefs can be restored, and new forms with protective functions can be made, forming a protected space of architectural environment for preschool education.

\subsubsection{Method of complementing the natural landscape}

Or otherwise the use of naturalness method, which involves the organic inclusion in the structure of existing landscapes objects for construction, without destroying their integrity and reasonably correcting [10]. The combination of architectural forms, based on natural analogues, the use of smooth shapes in combination with unified elements - provide an excellent opportunity to effectively solve many problems. These include: preserving and supplementing natural landscapes, increasing the artistic qualities of architectural volume of the building, returning the plots used for construction to recreational resource base, as well as providing microclimate parameters with minimal energy consumption.

\subsubsection{Method of incorporating green components into the internal building frame}

This method allows to include in the building structure, an artificially created natural environment in the form of "phyto-modules", which allows to form within the building specialized zones with different microclimatic parameters, some of which can serve as a kind of buffer between the main building volume and the aggressive environment. "Phytomodules" contribute to enrichment of the internal environment of architectural space, creating additional conditions for contact with nature for preschool children.

\subsubsection{Method of inclusion of natural component of walking area into internal structure of architectural space}

This method can be carried out by combining indoor and outdoor spaces by bringing the walking areas closer to the entrances allows to be closer to nature, which is akin to the parameters of the homestead plot and the living unit of an individual house.

In this sense of creating a comfortable protective environment in Ural region is greatly influenced by the placement of the promenade in relation to the building for preschool education. Optimal conditions that activate the protective function of the architectural environment is the maximum proximity of walkway to group unit entrance. In this case, the internal group unit space merges with the external one, bypassing the gap laid by the public territory.

So, the input element plays the role of a communication node - a distributor, as well as a play module in the form of a slide with a rope descent. The idea of bringing the walking area closer to exit from the group will help children to strengthen the sense of ownership and belonging of the given object to a certain group, bring natural elements closer to group units. 


\subsubsection{Method of inclusion on multi-component lighting by natural light}

The method of combining different forms of lighting involves the inclusion of various architectural combinations in the composition of the building, as well as the inclusion of overhead and overhead-side lighting through the window openings, reflective systems to light recreational areas, creating light halls, atrium spaces in exhibition areas, recreation, waiting areas (corridors and halls), in group rooms - this allows a child to contact the outside environment, time of day, weather conditions. To develop a sense of community with nature, and at the same time protection, calmness, peace, creating an opportunity to fill the inner world with new emotions baby.

\subsubsection{Method of inclusion of an ecological path in the structure of the complex}

The creation of ecological trails - a fairly new approach to the organization of architectural space for preschool education. At the same time, this phenomenon for the most part falls on the teachers' shoulders, and does not in any way affect the features of the building's architecture formation. At the same time, the use of this method could form the basis of building volume composition, providing an opportunity to reveal the natural environment potential, creating many angles to perceive the environment; become part of the creative function of children, bringing the natural components closer to themselves, actively participating in shaping the world around them, not excluding humans as creators

\section{Conclusions}

Considering the problem of ecologization of architectural space for preschool education in the Ural region this study contributes to a qualitative change in the architectural environment for preschool education in the application of a particular method, pursuing the main goal - to demonstrate the right attitude of children to nature. Moreover, given that this typology has already been introduced in most countries in one way or another.

The above methods for including a component of an environmentally friendly architectural environment are not limited to the above set of measures. This is a field of activity that constantly needs new suggestions from different specialists. But it explicitly identified areas to be followed and developed, to introduce them into the practice of architectural design. This provides a tremendous incentive to keep moving forward and putting the grain that has been lost today into the architecture of preschool buildings. Otherwise, children will not get what they sincerely deserve from nature. It is worth remembering that environmental content is a crucial factor in this process. A rich, broad environment will constantly present the possibility of alternative choices for creativity. An uninhibited, impersonal environment limits the opportunities for healthy growth and development, both as an individual and as a group.

The task of specialists-architects to help children, to love nature, bringing up in the appropriate environment, demonstrating a model of unparalleled union "man and nature".

\section{References}

1. E. A. Dorozhkina, IOP Conf. Series: Materials Science and Engineering, 451 (2018)

2. O. Finaeva, IOP Conf. Series: Materials Science and Engineering, 451 (2018)

3. E. A. Dorozhkina, IOP Conf. Series: Materials Science and Engineering, 4512018

4. I. Yu. Shelekhov, V. V. Pozhidaev, T. I. Shishelova, IOP Conf. Series: Materials Science and Engineering, 451 (2018) 
5. A. Giyazov, B. I. Giyazov, Yu. G. Baratov, Science and Innovation, 1 (2017)

6. A. N. Gushchin, M. N. Divakova, N. S. Mironova, IOP Conf. Series: Materials Science and Engineering, 451 (2018)

7. E. Lyaskovskaya, G. Khalilova and K. Shmykova, IOP Conf. Series: Materials Science and Engineering, 451 (2018)

8. N. A. Saprykina, Ya. A. Saprykin, IOP Conf. Series: Materials Science and Engineering, 451 (2018)

9. S. A. Ivanov, N. L. Abramova, Scientific dialogue, 9(57), 283 (2016)

10. A. V. Merenkov, N. S. Akchurina, T. M. Matveeva, IOP Conf. Series: Materials Science and Engineering, 687 (2019) 